\section{In Memoriam: Rustum Roy}

\author{
Co-founder of the \\ Materials Research Society \\ (1924-2010)
}

age 17) and his MSc degree in physical chemistry at Patna University, and started research on the most "useful" mineral resource of the region-mica.

In 1945, Roy was among 80 students selected for overseas training. In 1946 he was assigned to study mineral-chemistry at Penn State. Roy's goal was to absorb the best of U.S. culture, and its science, to take home to serve India.

Fate intervened when he met Della Martin, a graduate student who was assigned to share the same laboratory with Roy. He received his $\mathrm{PhD}$ degree on June 7 th and they were married on June 8th, 1948. Roy remained at Penn State in order to work with his mentor, E.F. Osborn, and within a year had developed the conceptual basis and first

the dean. In less than eight years, the SST program was turning out more PhD graduates than any department on campus.

In 1962, the first stand-alone "Interdisciplinary Laboratory for Materials Research" was created as a faculty tenure-granting unit. Roy was appointed director, where he served for 23 years. During his tenure, the MRL attracted top international scientists across a range of disciplines and Penn State was to become a landmark in scientific education and research.

Following the founding of MRS (which had its first home at Penn State; Ernest Hawk as its first staff person, followed by John B. Ballance, executive director), the success of MRS meetings was dramatic and the size of the meetings grew rapidly. One of Roy's major impacts on the MRS activities was the generation of a large number of sequential symposia on "The Scientific Basis of Nuclear Waste Management," which had a major influence on the field.

Roy's research continued to advance the boundaries of science and technology up to the present, including seminal research in the emerging field of water science.

In addition to scientific rewhich he was assigned to the National Ceramic Laboratory in Calcutta. At Penn State Roy held positions as Evan Pugh Professor of the Solid State (the University's highest honor); as Professor of Science, Technology, and Society; and as Professor of Geochemistry. He also was a Distinguished Professor

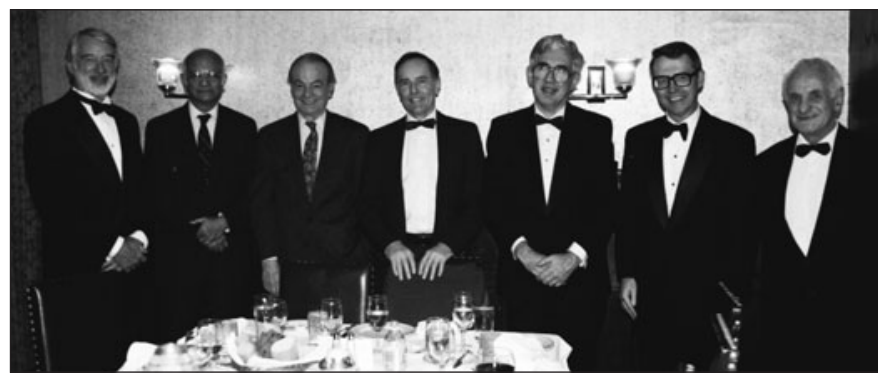

Rustum Roy (second from the left) at the Founders' Dinner during the 1993 Materials Research Society Fall Meeting. of Materials at Arizona State University, and a Visiting Professor of Medicine at the University of Arizona.

His work has been recognized by his election to five separate National Academies of Engineering/Science: of the United States, Sweden, India, Japan, and Russia. He had the Order of the Rising Sun with Gold Rays conferred on him by the Emperor of Japan.

Roy completed his BSc degree (at experimental proof of the "sol-gel" process, perhaps his most influential discovery in science.

In 1957, Roy became full professor. Pursuing his goal of interdisciplinary education and research in 1959-1960, Roy chaired Penn State's MS/PhD degree program in Solid State Technology, which was administered not by any department, but by an interdisciplinary group of faculty reporting directly to search, a hallmark of all his activity was his dedication to breaking artificial boundaries in order to integrate science, religion, education, health, art, and social action for human benefit. He chaired for many years the Science and Society Sector of President Mikhail Gorbachev's State of the World forum. He was founder and chair of Friends of Health, served as co-chair of the Chopra Foundation, and hosted a live Internet talk radio show on VoiceAmerica.com.

Roy was an endless fount of provocative ideas.

Ron Roy

Associate, Kacvinsky Daisak PLLC Della Roy

The Pennsylvania State University The authors thank Subhash Mahajan and John B. Ballance for their contributions. 